\title{
Polar Alkoxy Group and Pyridyl Effects on the Mesomorphic Behavior of New Non-Symmetrical Schiff Base Liquid Crystals
}

\author{
Sayed Z. Mohammady 1,2,*®D, Daifallah M. Aldhayan ${ }^{1}$, Mohammed A. Alshammri ${ }^{1}$, Ayoub K. Alshammari ${ }^{1}$, \\ Mohammed Alazmi ${ }^{3}$, Kanubhai D. Katariya ${ }^{4}$, Mariusz Jaremko ${ }^{5}$ and Mohamed Hagar ${ }^{3, *}$ \\ 1 Department of Chemistry, College of Science, King Saud University, Riyadh 11451, Saudi Arabia; \\ aldhayan@ksu.edu.sa (D.M.A.); Alshammri@ksu.edu.sa (M.A.A.); 442106682@student.ksu.edu.sa (A.K.A.) \\ 2 Department of Chemistry, Faculty of Science, Cairo University, Giza 12613, Egypt \\ 3 Chemistry Department, Faculty of Science, Alexandria University, Alexandria 21321, Egypt; \\ Mohammadalazmmi@gmail.com \\ 4 Department of Chemistry, Faculty of Science, The Maharaja Sayajirao University of Baroda, Vadodara 390002, \\ India; kanukatariya-chemphd@msubaroda.ac.in \\ 5 Biological and Environmental Sciences \& Engineering Division (BESE), King Abdullah University of Science \\ and Technology (KAUST), Thuwal 23955-6900, Saudi Arabia; mariusz.jaremko@kaust.edu.sa \\ * Correspondence: sahmed2.c@ksu.edu.sa (S.Z.M.); mohamed.hagar@alexu.edu.eg (M.H.)
}

Citation: Mohammady, S.Z.; Aldhayan, D.M.; Alshammri, M.A.; Alshammari, A.K.; Alazmi, M.; Katariya, K.D.; Jaremko, M.; Hagar, M. Polar Alkoxy Group and Pyridyl Effects on the Mesomorphic Behavior of New Non-Symmetrical Schiff Base Liquid Crystals. Symmetry 2021, 13, 1832. https://doi.org/10.3390/ sym13101832

Academic Editors: György Keglevich, Shoichi Ishihara and Sadahito UTO

Received: 16 August 2021

Accepted: 22 September 2021

Published: 1 October 2021

Publisher's Note: MDPI stays neutral with regard to jurisdictional claims in published maps and institutional affiliations.

Copyright: (c) 2021 by the authors. Licensee MDPI, Basel, Switzerland. This article is an open access article distributed under the terms and conditions of the Creative Commons Attribution (CC BY) license (https:/ / creativecommons.org/licenses/by/ $4.0 /)$.
Abstract: A series of non-symmetrical Schiff base liquid crystals were prepared and investigated. Schiff bases of p-alkyloxy aniline derivatives and 4-phenyl pyridine-4'-carbaldehyde were synthesized. The terminal alkoxy groups substituting aniline are of varied chain length, namely C6, C8, and C16. The structures of the compounds were confirmed via ${ }^{1} \mathrm{H}$ NMR and ${ }^{13} \mathrm{C}$ NMR spectroscopy. Different mesophases of the samples were thermally and optically characterized by differential thermal analysis (DSC) and polarized optical microscopy (POM). All samples revealed enantiotropic smectic B ( $\mathrm{SmB}$ ) and smectic A (SmA) mesophases. The results obtained were further correlated with the density functional theory (DFT) theoretical calculations. The results are compared to a series of compounds bearing biphenyl moiety in their mesogens. The thermal stabilities of the different mesophase reduced upon the increment of the alkoxy chain length. The temperature ranges of both the smectic mesophases of new compounds bearing the 4-phenyl pyridine moiety are generally expanded higher than the other series. In addition, the total mesophase range is greater in the new compounds when compared to their biphenyl analogues. The DFT results were investigated in terms of the molecular geometries and the frontier molecular orbitals as well as the charge distribution mapping to show and illustrate the difference in the mesomorphic properties.

Keywords: liquid crystal; schiff base; biphenyl; 4-phenyl pyridine; DFT

\section{Introduction}

A unique state of matter called the Liquid crystalline state gained much importance and attracted considerable attention both in the basic sciences and technological applications because of a variety of advanced applications including digital displays, sensors, liquid crystal displays (LCDs), high-performance polymers, transporting of electron, ion or molecule and drug-delivery systems, and hybrid composites [1-5]. Rod-like liquid crystalline materials called calamitic mesogens (possessing a rigid core with two or more aromatic rings linked by connecting groups and flexible terminal chains), have attracted remarkable attention over recent decades due to their ability to display a wide range of technologically important liquid crystal phases [6-9]. With a variety of structures of rod-like molecules, they display some potential applications by changing their physical properties including dielectric anisotropy $(\Delta \varepsilon)$, birefringence $(\Delta n)$, rotational viscosity and mesophase range for liquid crystal compounds [10-13].

It was observed that the mesomorphic properties of thermotropic calamitic LC are mostly influenced by the nature of terminal chains including alkyl, alkyloxy, perfluorinated 
chain, ester or acyl group, or introduction of heteroatom into terminal chains [14-17]. Recently, a huge number of structurally varied thermotropic liquid crystals consist of polar heteroatoms/heterocyclic systems were designed and synthesized [17-19]. A variety of materials synthesized based on five and six membered heterocyclic rings comprising one, two, or three nitrogen atoms gave rise to attracting mesomorphic properties. The enhanced attractive forces and layer formation properties due to molecular stacking and packing of these liquid crystals are attributed to the position of nitrogen atoms and the availability of their lone pair of electrons. The inclusion of a heteroatom or heterocyclic unit induces substantial effects such as polarizability, enhanced lateral and/or longitudinal dipole moment, increased intermolecular interaction, and impact the mesophase stability, phase transition temperatures and introduction of transverse dipole moment, often stimulating negative dielectric anisotropic properties due to the existence of lone-pair electrons on heteroatoms of rings [20]. The mesomorphic compounds with five-membered heterocyclic units such as 1,3,4-oxadiazole [21-23], 1,2,4-oxadiazole [24,25], isoxazole [26,27], 1,3,4thiadiazole [28,29], and thiophene [30-32] showed interesting mesomorphic properties. Recently, several structurally diverse liquid crystals based on pyridine were prepared and studied for their mesomorphic properties [33-35].

Furthermore, several liquid crystalline compounds with connecting units including imine, ester, ether, and azo to connect various aromatic rings were prepared and studied for their liquid crystal behavior [36-40]. Since the discovery of 4-methoxybenzylidene$4^{\prime}$-butylaniline at room temperature nematogen [41], much attention has been focused by the researchers as the introduction of Schiff base unit $(-\mathrm{CH}=\mathrm{N}-)$ promote the stability of mesophase by maintaining the linearity and rigidity. Recently, several thermotropic mesogens based on Schiff base with low molar mass have been synthesized, characterized and investigated [32,42,43].

Mesomorphic behavior of rod-like liquid crystal compounds is essentially reliant on the shape of molecule depending on molecular conformation [44,45]. Even a minor alteration in the structure of mesogens results in changes in their mesomorphic properties significantly. Moreover, the formation of mesophase, type of phase and its thermal stability largely dependent on the central connecting unit and the terminal groups/chains attached to mesogenic compounds [44,46]. Consequently, in the design of new mesogenic compounds the linking unit, terminal groups and flexible hydrocarbon chains are crucial.

\section{Materials and Methods}

All chemicals were purchased from TCI Company, Japan. Their purity is higher than $98 \%$. Schiff bases were prepared and recrystallized twice from ethanol/water mixture and were checked to be TLC pure, Scheme 1.

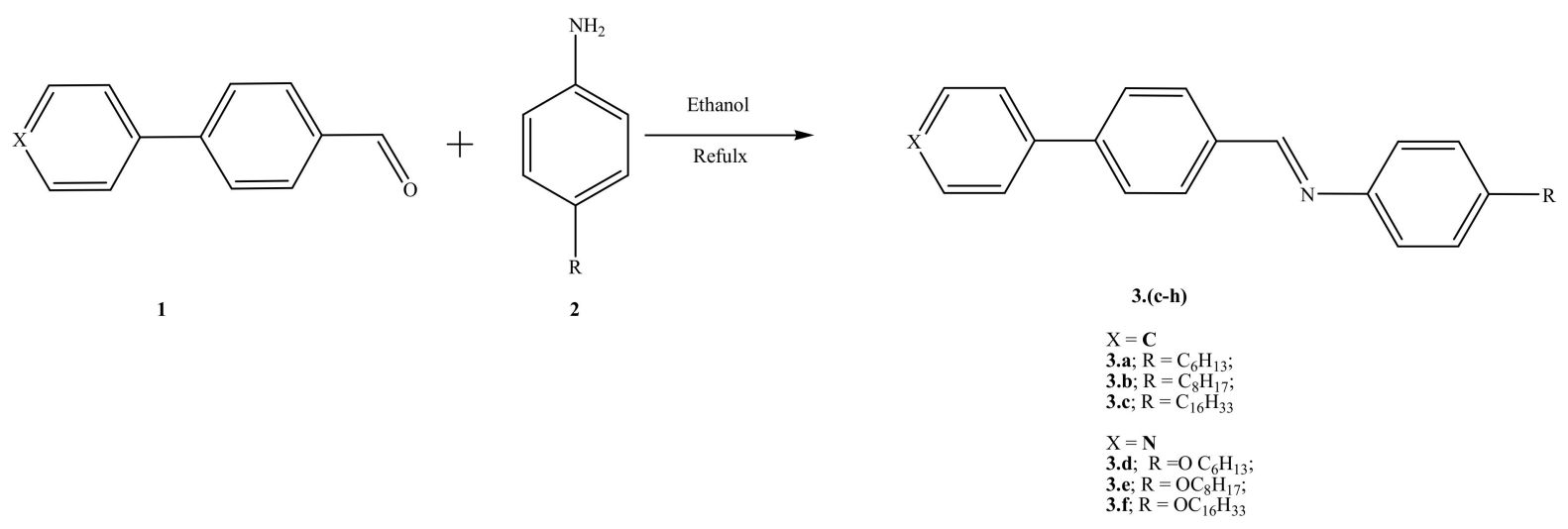

Scheme 1. Synthesis of N-arylidene-4-alkyloxbenzenamine 3a-f (samples 3.a, 3.b and 3.e are reported in Reference [47]). 


\section{Synthesis of N-Arylidene-4-alkyloxybenzenamine (3a-f)}

Alkyloxybenzaldehyde $(4.1 \mathrm{mmol})$ and 4 -arylamine $(4.1 \mathrm{mmol})$ equimolar equivalents were dissolved in ethanol $(10 \mathrm{~mL})$ and refluxed for two hours. The mixture was filtered after cooling to room temperature. TLC analysis showed that the obtained solid was washed with cold ethanol and recrystallized twice from hot ethanol to yield pure compounds.

(E)-N-(4-(Hexyloxy)phenyl)-1-(4-(pyridin-4-Yl)phenyl)methanimine (3.d)

Yield $=97 \%$, IR $\left(\mathrm{KBr}^{\mathrm{cm}} \mathbf{c m}^{-1}\right)$ : 3041, 2952, $2851(\mathrm{C}-\mathrm{H}), 1625(\mathrm{CH}=\mathrm{N}), 1597,1539,1511$, 1408, 1361, 1270, 1183, 1118, 887, 822, 808, 721; ${ }^{1} \mathbf{H}$ NMR (400 MHz, $\mathbf{C D C l}_{3}, \delta$ p pm): $0.93(\mathrm{t}$, $J=7.2 \mathrm{~Hz}, 3 \mathrm{H}), 1.34-1.39(\mathrm{~m}, 4 \mathrm{H}), 1.45-1.52(\mathrm{~m}, 2 \mathrm{H}), 1.78-1.85(\mathrm{~m}, 2 \mathrm{H}), 3.99(\mathrm{t}, J=6.4 \mathrm{~Hz}$, $2 \mathrm{H}), 6.96(\mathrm{dd}, J=6.8 \mathrm{~Hz}, 2 \mathrm{H}), 7.29(\mathrm{dd}, J=6.4 \mathrm{~Hz}, 2 \mathrm{H}), 7.57(\mathrm{dd}, J=4.4 \mathrm{~Hz}, 2 \mathrm{H}), 7.77(\mathrm{~d}$, $J=8.0 \mathrm{~Hz}, 2 \mathrm{H}), 8.01(\mathrm{~d}, J=8.4 \mathrm{~Hz}, 2 \mathrm{H}), 8.55(\mathrm{~s}, 1 \mathrm{H}), 8.71(\mathrm{dd}, J=4.4 \mathrm{~Hz}, 2 \mathrm{H}) ;{ }^{13} \mathrm{CNMR}$ (100 MHz, $\mathrm{CDCl}_{3}, \delta$ p pm): 14.10, 22.65, 25.76, 29.28, 31.63, 68.29, 115, 121.57, 122.33, 127.35, $129.24,137.12,140.33,144.30,147.46,150.42,157.00,158.17$.

(E)-N-(4-(Octyloxy)phenyl)-1-(4-(pyridin-4-Yl)phenyl)methanimine (3.e)

Yield $=95 \%$, IR $\left(\mathbf{K B r}, \mathbf{c m}^{-1}\right): 3045,2951,2852(\mathrm{C}-\mathrm{H}), 1621(\mathrm{CH}=\mathrm{N}), 1594,1533,1505$, 1402, 1361, 1275, 1181, 1117, 889, 822, 804, 721; ${ }^{1} \mathbf{H}$ NMR (400 MHz, $\mathrm{CDCl}_{3}, \delta$ ppm): $0.91(\mathrm{t}$, $J=6.8 \mathrm{~Hz}, 3 \mathrm{H}), 1.31-1.37(\mathrm{~m}, 8 \mathrm{H}), 1.45-1.52(\mathrm{~m}, 2 \mathrm{H}), 1.78-1.85(\mathrm{~m}, 2 \mathrm{H}), 3.99(\mathrm{t}, J=6.8 \mathrm{~Hz}$, $2 \mathrm{H}), 6.96(\mathrm{dd}, J=6.8 \mathrm{~Hz}, 2 \mathrm{H}), 7.29(\mathrm{dd}, J=6.8 \mathrm{~Hz}, 2 \mathrm{H}), 7.57(\mathrm{dd}, J=4.4 \mathrm{~Hz}, 2 \mathrm{H}), 7.75(\mathrm{~d}$, $J=8.0 \mathrm{~Hz}, 2 \mathrm{H}), 8.02(\mathrm{~d}, J=8.4 \mathrm{~Hz}, 2 \mathrm{H}), 8.55(\mathrm{~s}, 1 \mathrm{H}), 8.71(\mathrm{dd}, J=4.4 \mathrm{~Hz}, 2 \mathrm{H}) ;{ }^{13} \mathrm{CNMR}$ (100 MHz, $\mathrm{CDCl}_{3}$, ठ p ppm):14.16, 22.70, 26.08, 29.28, 29.32, 29.41, 31.85, 68.30, 115.00, 121.57, $122.33,127.35,129.24,137.13,140.34,144.31,147.46,150.42,157.00,158.17$.

(E)-N-(4-(Hexadecyloxy)phenyl)-1-(4-(pyridin-4-Yl)phenyl)methanimine (3.f)

Yield $=$ 91\%, IR $\left(\mathbf{K B r}, \mathbf{~ c m}^{-1}\right)$ : 3038, 2955, $2847(\mathrm{C}-\mathrm{H}), 1618(\mathrm{CH}=\mathrm{N}), 1595,1534,1501$, 1405, 1365, 1277, 1182, 1115, 887, 822, 804, 720; ${ }^{1} \mathbf{H}$ NMR (400 MHz, $\mathrm{CDCl}_{3}, \delta$ ppm): $0.90(\mathrm{t}$, $J=6.4 \mathrm{~Hz}, 3 \mathrm{H}), 1.28(\mathrm{~m}, 26 \mathrm{H}), 1.73-1.85(\mathrm{~m}, 2 \mathrm{H}), 4.00(\mathrm{t}, J=6.4 \mathrm{~Hz}, 2 \mathrm{H}), 6.96(\mathrm{dd}, J=8.4 \mathrm{~Hz}$, $2 \mathrm{H}), 7.29(\mathrm{~d}, J=8.4 \mathrm{~Hz}, 2 \mathrm{H}), 7.57(\mathrm{~d}, J=5.6 \mathrm{~Hz}, 2 \mathrm{H}), 7.77(\mathrm{~d}, J=8.4 \mathrm{~Hz}, 2 \mathrm{H}), 8.02(\mathrm{~d}$, $J=8.0 \mathrm{~Hz}, 2 \mathrm{H}), 8.56(\mathrm{~s}, 1 \mathrm{H}), 8.71(\mathrm{~d}, J=5.6 \mathrm{~Hz}, 2 \mathrm{H})$.

${ }^{1} \mathrm{H}$ NMR and ${ }^{13} \mathrm{C}$ NMR results (Figures S1-S5) are given in the Supplementary Materials as following: Figure S1: ${ }^{1} \mathrm{H}$ NMR of compound (OC6) 3.d; Figure S2: ${ }^{13} \mathrm{C}$ NMR of compound (OC6) 3.d; Figure S3: ${ }^{1} \mathrm{H}$ NMR of compound (OC8) 3.e; Figure S4: ${ }^{13} \mathrm{C}$ NMR of compound (OC8) 3.e; Figure S5: ${ }^{1} \mathrm{H}$ NMR of compound 3a (OC16) 3.f.

The phase changes in the materials were determined by means of differential scanning calorimetry (DSC), DSC-60A, Shimadzu, Japan. The size of samples was in the range of 2-3 mg. Samples were encapsulated in Al pans and were heated or cooled in inert atmosphere (dry nitrogen atmosphere). Measurements were accomplished at $10.0^{\circ} \mathrm{C} / \mathrm{min}$. Samples were heated from room temperature to $200{ }^{\circ} \mathrm{C}$ and cooled back to room temperature at the same heating. The transition temperatures for the various phase changes were gained from the endothermic peak minima of enthalpy. The accuracy of temperature recording was better than $1.0^{\circ} \mathrm{C}$.

\section{Results and Discussion}

\subsection{Synthesis and Characterization}

The ${ }^{1} \mathrm{H}$ NMR of compounds showed that the terminal methyl group protons were observed as a triplet at $\delta 0.91 \mathrm{ppm}$ whereas the protons of methylene group directly attached to the aromatic ring observed at $\delta 2.99 \mathrm{ppm}$ as a triplet. The appearance of singlet at $\delta 8.55 \mathrm{ppm}$ corresponding to imine linkage proton $(-\mathrm{CH}=\mathrm{N}-)$ confirmed the formation of Schiff base for prepared compounds. The protons near the nitrogen of the pyridine ring were observed as a doublet most upfield at $\delta 8.71 \mathrm{ppm}$. The rest of the aromatic and aliphatic protons were observed as per the substitution pattern of compounds. In the ${ }^{13} \mathrm{C}$ NMR spectra of new compounds, the terminal methyl carbon was observed most upfield $\delta 14.10 \mathrm{ppm}$ while methylene carbon directly attached to oxygen were observed at $\delta$ $68.29 \mathrm{ppm}$. The carbon of the imine linkage was appeared most downfield at $\delta 158.17 \mathrm{ppm}$ whereas two carbons in vicinity to nitrogen of pyridine ring were observed at $\delta 150.42 \mathrm{ppm}$. 
The rest of the carbons were observed as per the substitution pattern and in agreement with the structures of the new compounds.

\subsection{Mesomorphic Behavior}

Transition temperatures and the corresponding associated enthalpy changes of the prepared compounds were measured by DSC and displayed in Table 1. The DSC thermograms of the three new alkoxy derivative (3.d, 3.e and 3.f) are presented in Figure 1a-c. All the prepared compounds exhibited dimorphic enantiotropic mesomorphic characteristics whereby the corresponding endotherms were regarded as following according to the increase in temperature: crystalline to smectic B (Cryst.-SmB), SmB to smectic A (SmB-SmA) and SmA-isotropic (SmA-I) transitions. The SmB and SmA mesophases were specified by the existence of the standard Schlieren and focal-conic fan textures.

Table 1. Phase transitions: temperatures $\left(T,{ }^{\circ} \mathrm{C}\right)$ and enthalpies $(\Delta H, \mathrm{~kJ} / \mathrm{mol})$ for the prepared compounds 3.a-f. The abbreviations Cr-SmB, SmB-SmA, SmB-I, SmA-I, SmA-N, and N-I refer to the crystalline to smectic B, smectic B smectic A, smectic B to isotropic, smectic $\mathrm{A}$ to isotropic, smectic $\mathrm{A}$ to nematic and nematic to isotropic transitions, respectively. $\Delta H$ refers to the enthalpy changes in $\mathrm{kJ} / \mathrm{mol}$ for the different phase transitions.

\begin{tabular}{|c|c|c|c|c|c|c|c|c|c|c|}
\hline \multirow{2}{*}{ Compound } & ${ }^{\circ} \mathrm{C}$ & $\mathrm{kJ} / \mathrm{mol}$ & ${ }^{\circ} \mathrm{C}$ & $\mathrm{kJ} / \mathrm{mol}$ & ${ }^{\circ} \mathrm{C}$ & $\mathrm{kJ} / \mathrm{mol}$ & ${ }^{\circ} \mathrm{C}$ & $\mathrm{kJ} / \mathrm{mol}$ & ${ }^{\circ} \mathrm{C}$ & $\mathrm{kJ} / \mathrm{mol}$ \\
\hline & $\mathrm{T}_{\mathrm{Cr}-\mathrm{SmB}}$ & $\Delta \mathbf{H}_{\mathrm{Cr}-\mathrm{SmB}}$ & $\mathbf{T}_{\text {SmB-SmA }}$ & $\Delta \mathbf{H}_{\mathrm{SmB}-\mathrm{SmA}}$ & $\mathbf{T}_{\text {SmB-I }}$ & $\Delta \mathbf{H}_{\text {SmA-I }}$ & $\mathrm{T}_{\text {SmA-N }}$ & $\Delta \mathbf{H}_{\text {SmA-N }}$ & $\mathbf{T}_{\mathrm{N}-\mathrm{I}}$ & $\Delta \mathrm{H}_{\mathrm{N}-\mathrm{I}}$ \\
\hline 3.a (C6) & 86.2 & 28.09 & & & & & 128.0 & - & 135.0 & - \\
\hline $3 . b(C 8)$ & 95.1 & 76.02 & 130.0 & 3.03 & & & 132.2 & 1.77 & 134.5 & 0.46 \\
\hline 3.c (C16) & 110.9 & 119.75 & 112.7 & 3.78 & 118.6 & 3.71 & & & & \\
\hline 3.d $\left(-\mathrm{OC}_{6}\right)$ & 121.8 & 35.78 & 149.9 & 3.23 & 170.1 & 5.61 & & & & \\
\hline 3.e $\left(-\mathrm{OC}_{8}\right)$ & 113.9 & 21.23 & 146.0 & 2.37 & 168.1 & 3.76 & & & & \\
\hline 3.f $\left(-\mathrm{OC}_{16}\right)$ & 112.3 & 24.62 & 143.3 & 2.13 & 166.6 & 3.42 & & & & \\
\hline
\end{tabular}

It is worth noting that this study presents a continuation of our systematic work in which we investigate the effect of conjugation length on the mesomorphic behavior on model examples of LCs. In a recent article, we have investigated the effect of introducing 4phenyl pyridine moiety on LC molecules terminated with alkyl group [48]. The mesophases of new compounds were verified by observing their textures through POM (Figure 2). Observation of mesomorphic behavior of the new compounds bearing the 4-phenylpyridyl mesogens (3.d-f) under the POM showed enantiotropic dimorphic mesomorphism. After heating from crystalline phase to isotropic liquid and again cooling it from its isotropic liquid phase to crystalline phase, all new compounds verify the presence of two mesophases both via POM and DSC thermograms (Table 1). First, SmB phase texture (Figure 2a appears after melting, and later it turned out to SmA phase (Figure 2b) at elevated temperatures. The SmB and SmA mesophases were identified by the appearance of the standard Schlieren and focal-conic fan textures. All observed LC mesophase textures agree with the literature both with respect to their textures and the associated enthalpy changes recorded by DSC measurements $(\Delta \mathrm{H}$ values lies between 2.13 and $5.61 \mathrm{~kJ} / \mathrm{mol})$. 


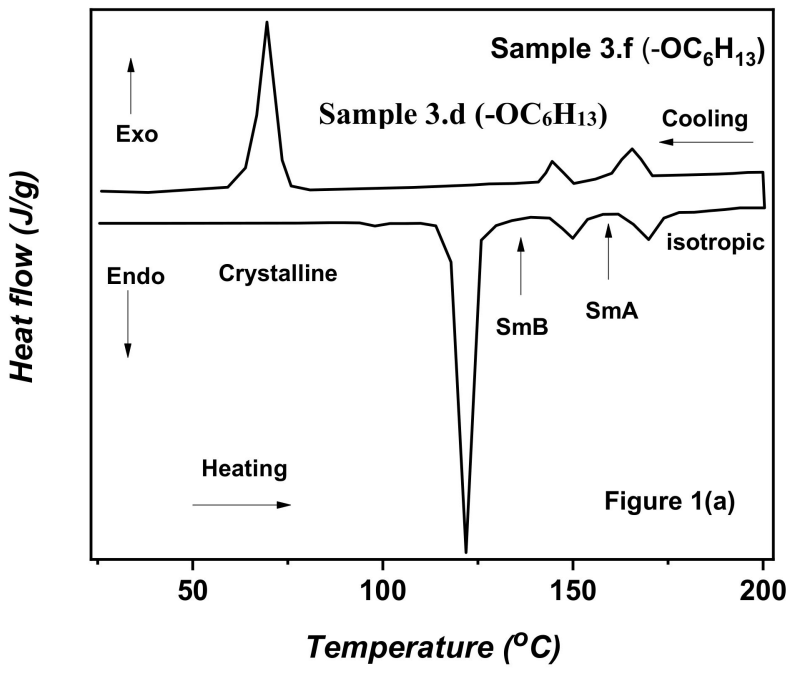

(a)

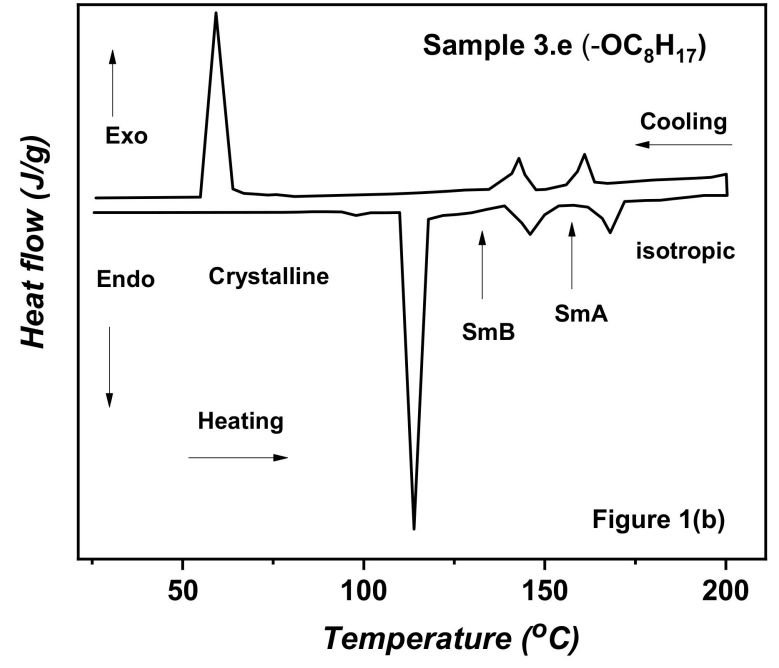

(b)

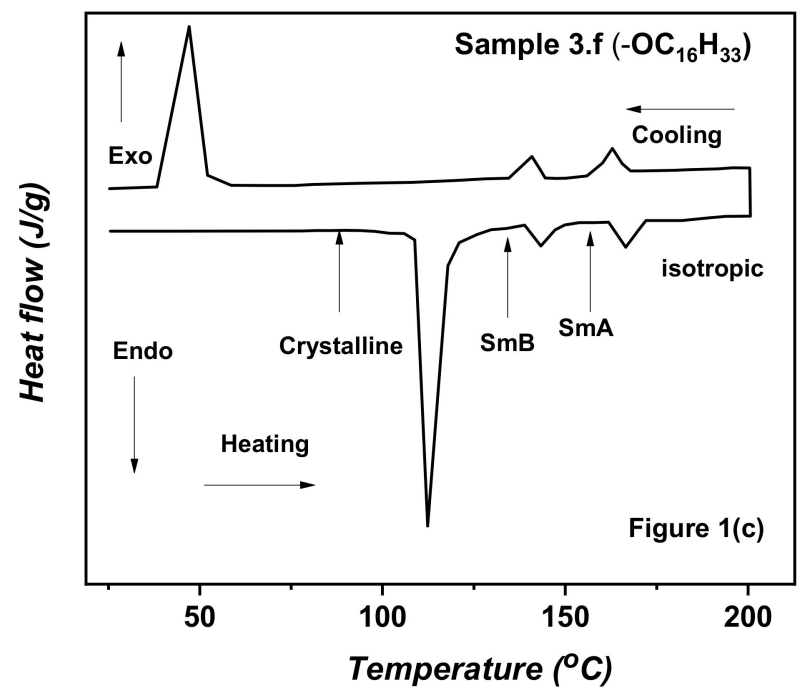

(c)

Figure 1. (a-c) DSC thermograms of the new compounds 3.d, 3.e and 3.f during heating and cooling cycles $\left(10^{\circ} \mathrm{C} \mathrm{min}{ }^{-1}\right)$.
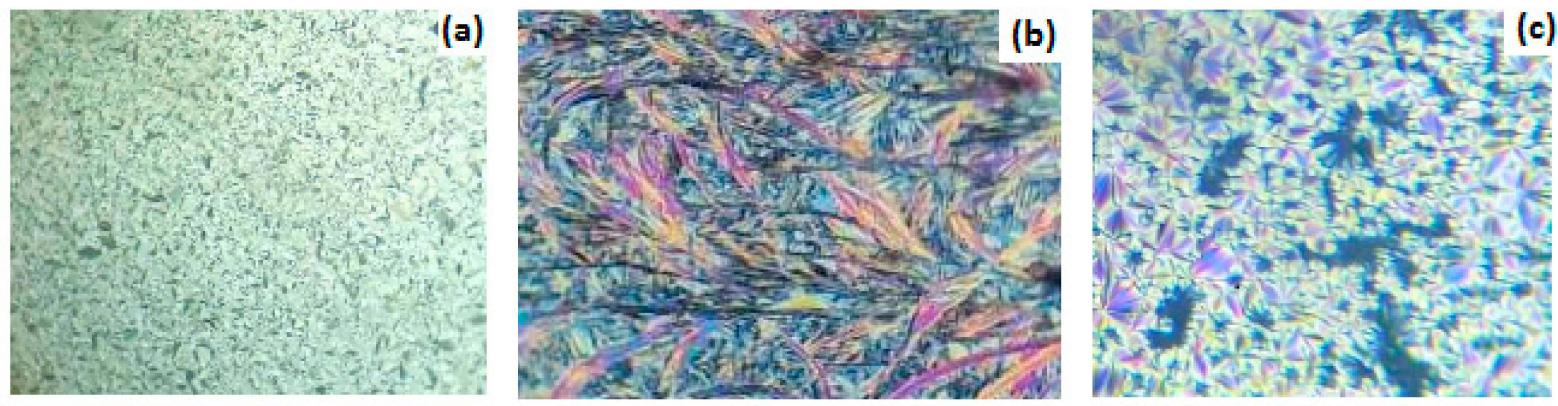

Figure 2. Mesophase textures observed by POM during heating cycle of compound 3.d Smectic B phase at $130.0^{\circ} \mathrm{C}(\mathbf{a})$, 3.e Smectic A phase at $158.0^{\circ} \mathrm{C}(\mathbf{b})$, 3.f Smectic A phase at $162.0^{\circ} \mathrm{C}(\mathbf{c})$.

The effect of variation of the alkyloxy chain length on the mesomorphic behavior of the new compounds is displayed in Figure 3. 


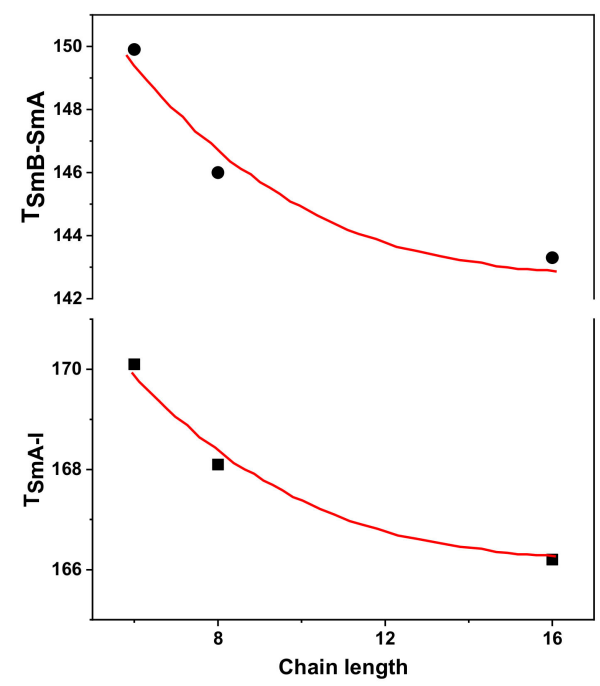

Figure 3. Dependence of the mesophase transition temperatures on the alkyloxy chain length.

It is observed that the transition temperatures of $\mathrm{SmB} / \mathrm{SmA}$ mesophase transition decreases as alkoxy chain length increase. In the same manner, the SmA-I transition temperatures showed similar response upon the increase of the terminal alkoxy group (C6 to $\mathrm{C} 16)$.

The variation of mesophase temperature ranges of the different observed textures ( $\mathrm{SmB}$ and $\mathrm{SmA}$ ) in the new compounds 3.d to 3.f is compared to the results obtained for mesomprohic compounds bearing biphenyl moiety and terminated with long chain alkyl groups rather than our new series containing 4-phenyl pyridyl group in their mesogens and terminated with long chains of alkoxy groups. The results are shown in Table 2.

Table 2. Variation of mesophase temperature ranges of the different observed textures for the mesomorphic compounds bearing biphenyl group (alkyl terminated) rather than 4-phenyl pyridine (alkoxy terminated) ends in their mesogens.

\begin{tabular}{ccccc}
\hline \multirow{2}{*}{$\begin{array}{c}\text { Alkyl Chain } \\
\text { Length }\end{array}$} & Biphenyl & $\begin{array}{c}\text { 4-Phenyl } \\
\text { Pyridine }\end{array}$ & Biphenyl & $\begin{array}{c}\text { 4-Phenyl } \\
\text { Pyridine }\end{array}$ \\
\cline { 2 - 5 } & 41.8 & 28.1 & - & 20.2 \\
\hline C6 & 34.8 & 35.1 & 2.2 & 22.1 \\
\hline C8 & 1.8 & 31.0 & 5.9 & 23.3 \\
\hline C16 & & &
\end{tabular}

The increased mesophase stabilities and broadening in the SmA mesomorphic temperature range in the compounds $\mathbf{3 d}-\mathbf{f}$ can be rationalized to two different factors. The first factor is the increased pi-pi stacking arising from the extra contribution of the $\mathrm{N}$-atom of the pyridine ring to the total conjugated electrons along the mesogen. The second factor is the presence of two lone pairs of electrons on the oxygen atom of the alkoxy chains which is directly fused to the mesogenic group. The presence of the lone pairs of electrons on the oxygen atom may lead to extra conjugation which in turn increases the length of the mesogenic group (increased pi-pi stacking). Consequently, the mesophase stability is largely increased in alkoxy terminated series of LCs compared to the biphenyl series ended with alkyl chains. This elevation in pi-pi stacking can explain the promoted SmB and SmA mesomorphic order rather than the nematic one even for the sample bearing relatively short hexyloxy chain length (3.d). Comparing the effect in the present study with LC having 4-phenyl pyridine and terminated with alkyl groups, the effects of introducing the above explained two factors were more pronounced [48]. 


\subsection{DFT Calculations}

Gaussian 9 was used to carry out theoretical DFT computations in the gas phase using DFT and B3LYP 6-311g $(\mathrm{d}, \mathrm{p})$ base site. All optimized structures were found to be stable due to the lack of the imaginary frequency. The results of the theoretical calculations of the studied compounds 3.a-f reveal a non-planar geometry (Figure 4). The phenyl rings, on the other hand, are not coplanar, and the twist angle of the $\mathrm{CH}=\mathrm{N}$ is affected presence of the pyridine atom that affect the degree of aromaticity conjugated arylidene component. Furthermore, the biphenyl ring and its pyridyl derivative are significantly different in the degree of the aromaticity and consequently the presence of $\mathrm{N}$ - heteroatom affects the angle deviated from co-planarity. The twist $\mathrm{CH}=\mathrm{N}$ angle $(\theta)=7.8^{\circ}$ for the hexyl derivative 3.a of the biphenyl and $4.6^{\circ}$ for its pyridyl derivative 3.d. The pyridyl derivative 3.e $(\theta)=7.8^{\circ}$ had the higher twist angle, while its longest chain length $(C=16)$ derivative $3 . f$ had twist angle $(\theta)=9.3^{\circ}$. The result of the difference in twist angle of the alkoxy derivatives of the pyridyl and its alkyl derivatives of the biphenyl one could be explained in terms of better conjugation of the $\pi$-cloud of aromatic rings with the imino group with the alkoxy one of higher mesomeric resonance effect rather than the hyper conjugated alkyl group, and as a result of the high conjugation, arylidene system is more enforced to be more planar in the case of the alkoxypyridyl derivatives. While these theoretical molecular geometries may be a good predictor of the preferred molecular structure in the gas phase, the presence of these compounds in liquid crystalline matter condensed phases with a different lowest energy and more elongated species will be favored [49].

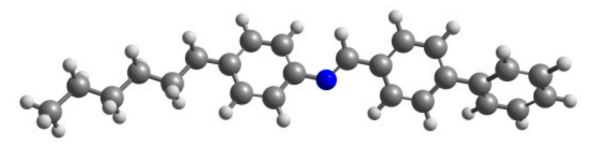

3.a

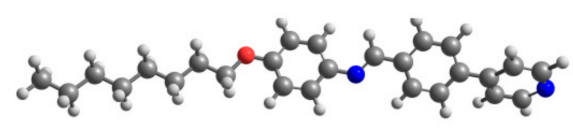

3.e

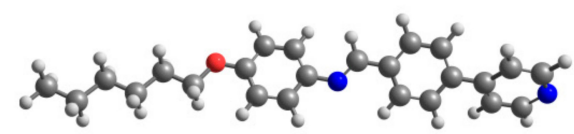

3.d

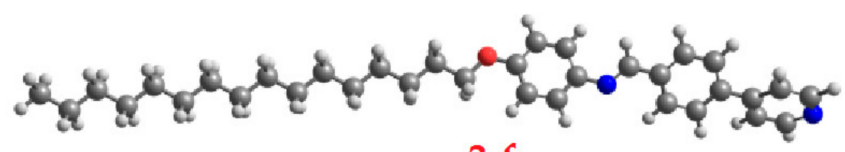

3.f

Figure 4. Optimized geometrical structure of the prepared compounds 3.a,d-f.

\subsection{Frontier Molecular Orbitals (FMOs)}

The results of the calculated plots of the synthesized compounds frontier molecular orbitals HOMO (highest occupied) and LUMO (lowest unoccupied) are shown in Table 3 and Figure 5. Figure 5 shows how the electron densities of the sites involved in LUMO and HOMO generation are localized on the pyridyl part and its conjugated rings. On the other hand, the electron densities of the FMOs were affected by the degree of conjugated rings affected by the polar alkoxy group as well as the presence of the hetaryl atom. Furthermore, the degree of conjugation and the existence of the $\mathrm{N}$-atom had a substantial impact on the energy levels of the FMOs and the energy gap between them. The presence of a more aromatic ring in the biphenyl derivatives affects the levels of the frontier molecular orbitals. The energy level of the FMOs is dramatically reduced when the $\mathrm{N}$-atom replaces the carbon. Furthermore, the energy difference between the FMOs was significantly altered by the extraconjugation of the alkoxy derivatives $\mathbf{3 . d - f}$ due to the resonance effect. The pyridyl derivative, on the other hand, showed a greater decrease in the energy gap than the phenyl derivative. This was demonstrated by increases in co-planarity in the case of the pyridyl derivative with respect to its phenyl, which resulted in additional more conjugation and a decrease in the FMOs energy gab. On the other hand, there is no difference in the FMOs energy gab and energy difference with the longer chain lengths. 
Table 3. FMO Energies e. V. and their values for the prepared compounds 3.a,d-f.

\begin{tabular}{cccc}
\hline Compounds & HOMO & LUMO & $\Delta \mathbf{E}$ \\
\hline 3.a & -5.75 & -1.85 & 3.90 \\
\hline 3.d & -5.77 & -2.10 & 3.67 \\
\hline 3.e & -5.76 & -2.10 & 3.66 \\
\hline 3.f & -5.77 & -2.11 & 3.66 \\
\hline
\end{tabular}
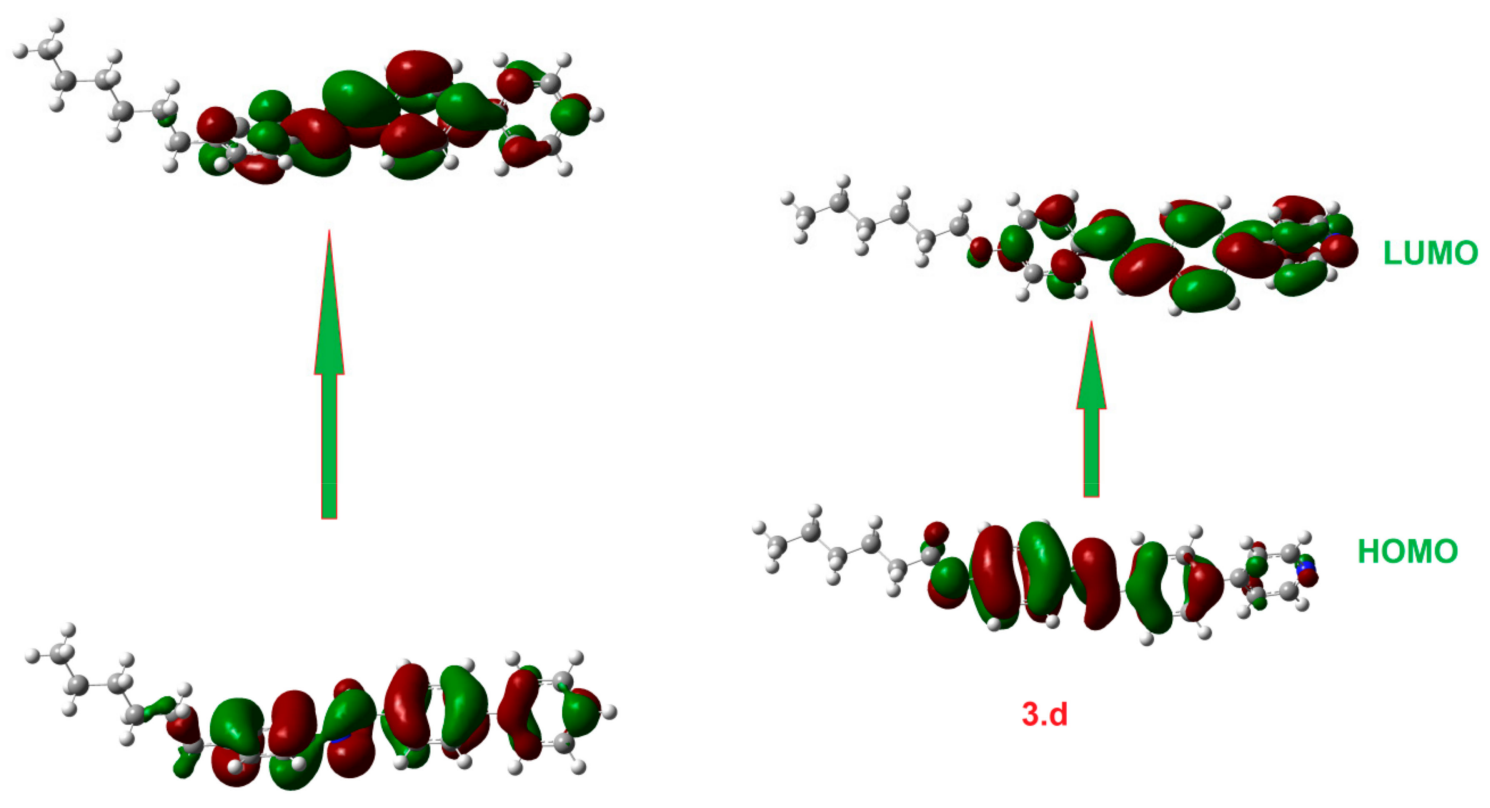

3.d

3.a

Figure 5. The calculated plots for the prepared compounds 3.a,d of the frontier molecular orbitals.

\subsection{Molecular Electrostatic Potential (MEP)}

According to molecular electrostatic potential (MEP), the charge distribution map for the synthesized compounds 3.a,d-f was estimated using the same method of calculations with the same basis sets as shown in Figure 6. Furthermore, the molecular electrostatic potential (MEP) is an important parameter to understand when analyzing the electron density distribution over molecules [49-51]. MEP is also one of the one of excellent tool to predict the intermolecular and/or intramolecular interactions. The existence of the polar $\mathrm{N}$-atom and the connecting $\mathrm{CH}=\mathrm{N}$ group of the examined compounds had an impact on the localization of the iso-electronic density of the electron rich and electron deficient areas. The Schiff base part $\mathrm{CH}=\mathrm{N}$ group has the lowest electron density, whereas the terminal alkoxy chain has the maximum electron density. The anticipated charge distribution maps could be used to illustrate how liquid crystals molecular structure assist mesophase behavior change. 


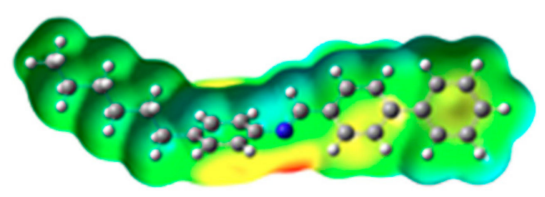

3.a

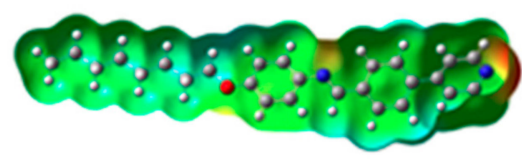

3.e

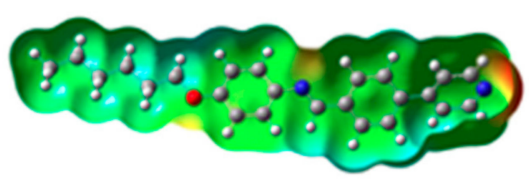

3.d

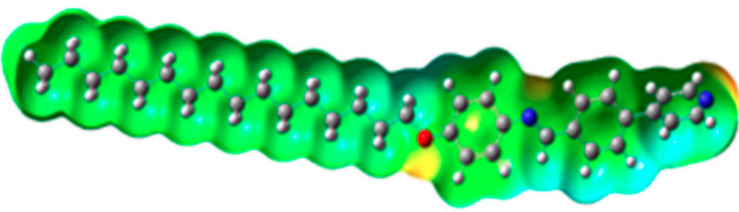

3.f

Figure 6. Molecular electrostatic potentials (Hartree) for the prepared compounds 3.a,d-f.

\section{Conclusions}

A novel series of Schiff base liquid crystals were prepared and investigated. Schiff bases of p-alkyloxy aniline derivatives and 4-phenylpyridine- 4 '-carbaldehyde were synthesized. The terminal alkoxy groups substituting aniline are of varied chain length, namely C6, C8, and C16. All samples revealed enantiotropic smectic B (SmB) and smectic A (SmA) mesophases. The results are compared to two series of compounds bearing pyridine and biphenyl, respectively, in their mesogens. The thermal stabilities of the different mesophase reduced upon the increment of the alkoxy chain length. The temperature ranges of both the smectic mesophases of new compounds bearing the 4-phenyl pyridine moiety are generally expanded higher than the other two series. In addition, the total mesophase range is greater in the new compounds when compared to their biphenyl analogues. The increased mesophase stabilities and broadening in the SmA mesomorphic temperature range in the new compounds were rationalized to the increased pi-pi stacking arising from the extra contribution of the $\mathrm{N}$-atom of the pyridine ring. A second factor that may contribute effectively is the lone pairs of electrons on the oxygen atom of the alkoxy chains. The presence of the lone pairs of electrons on the oxygen atom imparted extra conjugation and consequently, the mesophase stability increased. The results obtained were in a good agreement with the density functional theory (DFT) theoretical calculations. The result of DFT showed a difference in twist angle as well as the charge distribution maps of the alkoxy derivatives of the pyridyl and its alkyl derivatives and this could explain the difference in the mesomorphic properties.

Supplementary Materials: ${ }^{1} \mathrm{H}$ NMR and ${ }^{13} \mathrm{C}$ NMR results of the samples 3.d, 3.e and 3.f are given as supplementary materials. They are available at https://www.mdpi.com/article/10.3390/sym131 01832/s1, Figure S1: ${ }^{1} \mathrm{H}$ NMR of compound (OC6) 3.d; Figure S2: ${ }^{13} \mathrm{C}$ NMR of compound (OC6) 3.d; Figure S3: ${ }^{1} \mathrm{H}$ NMR of compound (OC8) 3.e; Figure S4: ${ }^{13} \mathrm{C}$ NMR of compound (OC8) 3.e; Figure S5: ${ }^{1} \mathrm{H}$ NMR of compound $3 a(\mathrm{OC} 16)$ 3.f.

Author Contributions: Conceptualization, S.Z.M. and M.H.; methodology, S.Z.M., D.M.A., M.A.A., A.K.A., M.A., K.D.K. and M.H.; validation, S.Z.M. and M.H.; investigation, S.Z.M., D.M.A., K.D.K., M.J. and M.H.; resources, S.Z.M. and M.H.; data curation, S.Z.M.; writing-original draft preparation, S.Z.M. and M.H.; writing-review and editing, S.Z.M., M.J. and M.H.; visualization, S.Z.M.; supervision, S.Z.M. and M.H.; project administration, S.Z.M.; funding acquisition, S.Z.M. All authors have read and agreed to the published version of the manuscript. 
Funding: This research was funded by the Deanship of Scientific Research at King Saud University for funding this work through the research group number (RG-1440-143).

Acknowledgments: The authors extend their appreciation to the Deanship of Scientific Research at King Saud University for funding this work through the research group number (RG-1440-143).

Conflicts of Interest: The authors declare no conflict of interest.

\section{References}

1. Alberti, G.; Atwood, J.L. Comprehensive Supramolecular Chemistry. 7. Solid-State Supramolecular Chemistry: Two-And ThreeDimensional Inorganic Networks; Pergamon Press: Oxford, UK, 1996.

2. Schenning, A.; Crawford, G.P.; Broer, D.J. Liquid Crystal Sensors; CRC Press: Boca Raton, FL, USA, 2017.

3. Picken, S.; Sikkema, D.; Boerstoel, H.; Dingemans, T.; Van der Zwaag, S. Liquid crystal main-chain polymers for high-performance fibre applications. Liq. Cryst. 2011, 38, 1591-1605. [CrossRef]

4. Müller-Goymann, C. Physicochemical characterization of colloidal drug delivery systems such as reverse micelles, vesicles, liquid crystals and nanoparticles for topical administration. Eur. J. Pharm. Biopharm. 2004, 58, 343-356. [CrossRef]

5. $\quad$ Spengler, M.; Dong, R.Y.; Michal, C.A.; Hamad, W.Y.; MacLachlan, M.J.; Giese, M. Hydrogen-Bonded Liquid Crystals in Confined Spaces-Toward Photonic Hybrid Materials. Adv. Funct. Mater. 2018, 28, 1800207. [CrossRef]

6. De Gennes, P.-G.; Prost, J. The Physics of Liquid Crystals; Oxford University Press: Oxford, UK, 1993.

7. Hird, M. Fluorinated liquid crystals-properties and applications. Chem. Soc. Rev. 2007, 36, 2070-2095. [CrossRef]

8. Chigrinov, V.G. Liquid Crystal Devices: Physics and Applications; Artech House Publishers: Norwood, MA, USA, 1999.

9. Patil, N.V.; Sahoo, R.; Veerabhadraswamy, B.; Chakraborty, S.; Dhar, R.; Mathad, R.; Yelamaggad, C. Polarization of three-ring Schiff base ferroelectric liquid crystals. Liq. Cryst. 2020, 48, 1194-1205. [CrossRef]

10. Si, G.; Zhao, Y.; Leong, E.S.P.; Liu, Y.J. Liquid-crystal-enabled active plasmonics: A review. Materials 2014, 7, 1296-1317. [CrossRef] [PubMed]

11. Wang, L.; Lin, X.-W.; Liang, X.; Wu, J.-B.; Hu, W.; Zheng, Z.-G.; Jin, B.-B.; Qin, Y.-Q.; Lu, Y.-Q. Large birefringence liquid crystal material in terahertz range. Opt. Mater. Express 2012, 2, 1314-1319. [CrossRef]

12. Yun, H.J.; Jo, M.H.; Jang, I.W.; Lee, S.H.; Ahn, S.H.; Hur, H.J. Achieving high light efficiency and fast response time in fringe field switching mode using a liquid crystal with negative dielectric anisotropy. Liq. Cryst. 2012, 39, 1141-1148. [CrossRef]

13. Lapanik, V.; Sasnouski, G.; Timofeev, S.; Shepeleva, E.; Evtyushkin, G.; Haase, W. New highly anisotropic liquid crystal materials for high-frequency applications. Liq. Cryst. 2018, 45, 1242-1249. [CrossRef]

14. Luo, C.-C.; Jia, Y.-G.; Sun, B.-F.; Meng, F.-B. The effect of chain length in terminal groups on the mesomorphic behavior of novel (-)-menthol-based chiral liquid crystal compounds with a blue phase. New J. Chem. 2017, 41, 3677-3686. [CrossRef]

15. Cheng, Z.; Li, K.; Wang, F.; Wu, X.; Chen, X.; Xiao, J.; Zhang, H.; Cao, H.; Yang, H. Influence of linkage and terminal group on the liquid crystalline and helical twisting behaviours of cholesteryl esters. Liq. Cryst. 2011, 38, 803-812. [CrossRef]

16. Hagar, M.; Ahmed, H.; Aouad, M. Mesomorphic and DFT diversity of Schiff base derivatives bearing protruded methoxy groups. Liq. Cryst. 2020, 47, 2222-2233. [CrossRef]

17. Hagar, M.; Ahmed, H.; Saad, G. New calamitic thermotropic liquid crystals of 2-hydroxypyridine ester mesogenic core: Mesophase behaviour and DFT calculations. Liq. Cryst. 2020, 47, 114-124. [CrossRef]

18. Regis, E.; de Aguiar, L.O.; Tuzimoto, P.; Girotto, E.; Frizon, T.E.; Dal Bó, A.G.; Zapp, E.; Marra, R.; Gallardo, H.; Vieira, A.A. Effect of heteroatom exchange (S/Se) in the mesomorphism and physical properties of benzochalcogenodiazole-based liquid crystals. Dye. Pigment. 2018, 157, 109-116. [CrossRef]

19. Ong, L.-K.; Ha, S.-T.; Yeap, G.-Y.; Lin, H.-C. Heterocyclic pyridine-based liquid crystals: Synthesis and mesomorphic properties. Liq. Cryst. 2018, 45, 1574-1584. [CrossRef]

20. Rodrigues, L.D.; Sunil, D.; Chaithra, D.; Bhagavath, P. 1, 2, 3/1, 2, 4-Triazole containing liquid crystalline materials: An up-to-date review of their synthetic design and mesomorphic behavior. J. Mol. Liq. 2020, 297, 111909. [CrossRef]

21. Saha, S.K.; Paul, M.K. Mesomorphic and photophysical behaviour of 1, 3, 4-oxadiazole based hockey stick reactive mesogens. Liq. Cryst. 2019, 46, 386-396. [CrossRef]

22. Santos, A.B.; Manfredi, A.M.; Salla, C.A.; Farias, G.; Girotto, E.; Eccher, J.; Westphal, E.; Curcio, S.F.; Cazati, T.; Malvestiti, I. Highly luminescent liquid crystals by connecting 1, 3, 4-oxadiazole with thiazolo [5, 4-d] thiazole units. J. Mol. Liq. 2021, 321, 114887. [CrossRef]

23. Saha, S.K.; Mohiuddin, G.; Paul, M.K.; Gupta, S.P.; Khan, R.K.; Ghosh, S.; Pal, S.K. Polar switching and cybotactic nematic ordering in 1, 3, 4-thiadiazole-based short-core hockey stick-shaped fluorescent liquid crystals. ACS Omega 2019, 4, 7711-7722. [CrossRef]

24. Fouad, F.S.; Ness, T.; Wang, K.; Ruth, C.E.; Britton, S.; Twieg, R.J. Biphenylyl-1, 2, 4-oxadiazole based liquid crystals-synthesis, mesomorphism, effect of lateral monofluorination. Liq. Cryst. 2019, 46, 2281-2290. [CrossRef]

25. Ali, G.Q.; Tomi, I.H.R. Synthesis and characterization of new mesogenic esters derived from 1, 2, 4-oxadiazole and study the effect of alkoxy chain length in their liquid crystalline properties. Liq. Cryst. 2018, 45, 421-430. [CrossRef]

26. Kotian, S.Y.; Mohan, C.D.; Merlo, A.A.; Rangappa, S.; Nayak, S.C.; Rai, K.L.; Rangappa, K.S. Small molecule based five-membered heterocycles: A view of liquid crystalline properties beyond the biological applications. J. Mol. Liq. 2020, 297, 111686. [CrossRef] 
27. Fritsch, L.; Baptista, L.A.; Bechtold, I.H.; Araujo, G.; Mandle, R.J.; Merlo, A.A. Isoxazoline-and isoxazole-liquid crystalline schiff bases: A puzzling game dictated by entropy and enthalpy effects. J. Mol. Liq. 2020, 298, 111750. [CrossRef]

28. Olate, F.A.; Parra, M.L.; Vergara, J.M.; Barberá, J.; Dahrouch, M. Star-shaped molecules as functional materials based on 1, 3 , 5-benzenetriesters with pendant 1, 3, 4-thiadiazole groups: Liquid crystals, optical, solvatofluorochromic and electrochemical properties. Liq. Cryst. 2017, 44, 1173-1184. [CrossRef]

29. Sharma, V.S.; Shah, A.P.; Sharma, A.S. A new class of supramolecular liquid crystals derived from azo calix [4] arene functionalized 1, 3, 4-thiadiazole derivatives. New J. Chem. 2019, 43, 3556-3564. [CrossRef]

30. Wan, D.; Shi, F.; Che, Z.; Mo, L.; Hu, M.; Guo, Q.; Li, J.; An, Z.; Li, J. Introduction of 5, 6-dihydro-4 H-cyclopenta [b] thiophene core unit into phenyl-tolane: Expanding the mesophase range and increasing the birefringence and dielectric anisotropy of liquid crystal. Liq. Cryst. 2021. [CrossRef]

31. Wan, D.; Yang, X.; Li, J.; Hu, M.; Mo, L.; Che, Z.; Guo, Q.; An, Z.; Li, J. Synthesis and properties of 5, 6-dihydro-4H-cyclopenta [b] thiophene-based nematic liquid crystals: A new access to mesogens with high birefringence and large dielectric anisotropy. $J$. Mol. Liq. 2021, 327, 114827. [CrossRef]

32. Nafee, S.S.; Ahmed, H.; Hagar, M. Theoretical, experimental and optical study of new thiophene-based liquid crystals and their positional isomers. Liq. Cryst. 2020, 47, 1291-1302. [CrossRef]

33. Devadiga, D.; Ahipa, T. An Up-to-date Review on Halogen-Bonded Liquid Crystals. J. Mol. Liq. 2021, 333, 115961. [CrossRef]

34. Devadiga, D.; Ahipa, T. Heterodimeric hydrogen-bonded mesogens comprising pyridine moiety: A review. Liq. Cryst. Rev. 2020, 8, 5-28. [CrossRef]

35. Devadiga, D.; Ahipa, T. Recent synthetic advances in pyridine-based thermotropic mesogens. RSC Adv. 2019, 9, $23161-23228$. [CrossRef]

36. Nakum, K.J.; Katariya, K.D.; Jadeja, R.N. Synthesis, characterization, and mesomorphic properties of some new Schiff base homologues series and their Cu (II) complexes. Mol. Cryst. Liq. Cryst. 2020, 708, 1-13. [CrossRef]

37. Nakum, K.J.; Katariya, K.D.; Jadeja, R.; Prajapati, A. Schiff base of 4-n-alkoxy-2-hydroxy benzaldehyde with 4-amino acetophenone and their $\mathrm{Cu}$ (II) complexes: Synthesis, characterization and mesomorphic behavior. Mol. Cryst. Liq. Cryst. 2019, 690, 1-13. [CrossRef]

38. Al-Hamdani, U.J.; Abbo, H.S.; Al-Jaber, A.A.; Titinchi, S.J. New azo-benzothiazole based liquid crystals: Synthesis and study of the effect of lateral substituents on their liquid crystalline behaviour. Liq. Cryst. 2020, 47, 2257-2267. [CrossRef]

39. Nafee, S.S.; Hagar, M.; Ahmed, H.A.; Alhaddad, O.; El-Shishtawy, R.M.; Raffah, B.M. New two rings Schiff base liquid crystals; ball mill synthesis, mesomorphic, Hammett and DFT studies. J. Mol. Liq. 2020, 299, 112161. [CrossRef]

40. Arakawa, Y.; Ishida, Y.; Tsuji, H. Ether-and Thioether-Linked Naphthalene-Based Liquid-Crystal Dimers: Influence of Chalcogen Linkage and Mesogenic-Arm Symmetry on the Incidence and Stability of the Twist-Bend Nematic Phase. Chem.-A Eur. J. 2020, 26, 3767-3775. [CrossRef]

41. Kelker, H.; Scheurle, B. A liquid-crystalline (nematic) phase with a particularly low solidification point. Angew. Chem. Int. Ed. Engl. 1969, 8, 884-885. [CrossRef]

42. Ahmed, H.; Mansour, E.; Hagar, M. Mesomorphic study and DFT simulation of calamitic Schiff base liquid crystals with electronically different terminal groups and their binary mixtures. Liq. Cryst. 2020, 47, 2292-2304. [CrossRef]

43. Nafee, S.S.; Hagar, M.; Ahmed, H.A.; El-Shishtawy, R.M.; Raffah, B.M. The synthesis of new thermal stable schiff base/ester liquid crystals: A computational, mesomorphic, and optical study. Molecules 2019, 24, 3032. [CrossRef]

44. Hagar, M.; Ahmed, H.; El-Sayed, T.; Alnoman, R. Mesophase behavior and DFT conformational analysis of new symmetrical diester chalcone liquid crystals. J. Mol. Liq. 2019, 285, 96-105. [CrossRef]

45. Hagar, M.; Ahmed, H.; Alhaddad, O. New azobenzene-based natural fatty acid liquid crystals with low melting point: Synthesis, DFT calculations and binary mixtures. Liq. Cryst. 2019, 46, 2223-2234. [CrossRef]

46. Ahmed, H.A.; Hagar, M.; El-Sayed, T.H.; Alnoman, R.B. Schiff base/ester liquid crystals with different lateral substituents: Mesophase behaviour and DFT calculations. Liq. Cryst. 2019, 46, 1-11. [CrossRef]

47. Srinivasu, C.; Pisipati, V.G.K.M.; Prabhu, C.R.; Murty, P.N.; Lakshiminarayana, S. Phase Transitions in p-(Phenyl Benzylidene)-p1Alkylaniline Compounds: A Dilatometric Study. Z. Naturforsch. 2007, 62, 75-83. [CrossRef]

48. Zakaria, M.A.; Alazmi, M.; Katariya, K.D.; El Kilany, Y.; El Ashry, E.H.; Jaremko, M.; Hagar, M.; Mohammady, S.Z. Mesomorphic Behaviour and DFT Insight of Arylidene Schiff Base Liquid Crystals and Their Pyridine Impact Investigation. Crystals 2021, 11, 978. [CrossRef]

49. Politzer, P.; Murray, J.S. Relationships between dissociation energies and electrostatic potentials of $\mathrm{CNO}_{2}$ bonds: Applications to impact sensitivities. J. Mol. Struct. 1996, 376, 419-424. [CrossRef]

50. Scrocco, E.; Tomasi, J. Electronic molecular structure, reactivity and intermolecular forces: An euristic interpretation by means of electrostatic molecular potentials. In Advances in Quantum Chemistry; Elsevier: Amsterdam, The Netherlands, 1978; Volume 11, pp. 115-193.

51. Marks, T.J.; Ratner, M.A. Design, synthesis, and properties of molecule-based assemblies with large second-order optical nonlinearities. Angew. Chem. Int. Ed. Engl. 1995, 34, 155-173. [CrossRef] 